\title{
Systematic Reviews: Their Spot at Our Table
}

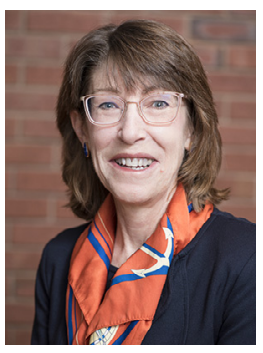

Systematic reviews have been around for a long time. JNEB published its first systematic review in 2008, analyzing the impact of peer education on dietary behaviors and health outcomes among Latinos. ${ }^{1}$ While peer education was found to have positive outcomes, the authors called for additional research concerning the peer educator themselves, the length and type of intervention, and of course, better standardization of questionnaires and scales. Because this paper has been cited in Scopus 113 times, I think the message was received and instigated or supported other work in this field. To me, this is a crucial reason for conducting and publishing systematic reviews.

Since that first systematic review, JNEB has published 24 others. They can be found in the Collections, Paper Types on jneb.org. There is a range of topics, including online nutrition courses, ${ }^{2}$ the effectiveness of interventions for communitydwelling older adults, ${ }^{3}$ college students, ${ }^{4}$ and adults with low income. ${ }^{5}$ Most called for better research, longer studies, and improved study design. Many of these calls to action would involve improved funding to implement. That may or may not happen, but it is important to document what we probably know and where research gaps are. These discussions should always be at the table, whether it is in a dissertation, at a conference, or in our own lab groups.

The findings of this issue's systematic review may seem intuitive: more frequent grocery shopping may lead to increased fruit and vegetable intake. ${ }^{6}$ The authors acknowledge that these were observational studies, not interventions, so caution must be taken. However, they pose an interesting issue of those using federal assistance and the limited shopping frequency capacity of many of these clients because of allotment distribution. If this were adjusted, and shopping more frequent, would the fruit and vegetable purchase and intake of these individuals with low income increase? The questions raised by our systematic reviews have implications not only for research, but also for policy and practice.

Although there are many guidelines for how to conduct a systematic review, and even college or online courses, we at JNEB are in the process of updating our guidelines. We've had discussions about the need to include only interventions that have been powered on the outcomes of interest, or to explain why this wasn't possible. Evaluation of the quality of the articles included is a must, but there are many tools available to conduct this evaluation. Are there some that are better than others? And finally, what about "failed searches" or those where the only conclusion is that more research is needed? Generally, JNEB does not accept these, unless the gap in the research is truly novel and moves nutrition education and behavior research forward. I must note, JNEB does not accept scoping or narrative reviews. These have a place in the literature, but JNEB prefers to include only those with the systematic review methodology.

Lastly, I wanted to alert you to JNEB's new tagline: Advancing Research, Practice, and Policy. Soon you will see it everywhere! I want to thank the editors, Journal Committee, publisher, and Society for working on this.

Karen Chapman-Novakofski PhD, RDN

Editor-in-Chief

Journal of Nutrition Education and Behavior

Advancing Research, Practice, and Policy

\section{REFERENCES}

1. Pérez-Escamilla R, Hromi-Fiedler A, Vega-López S, Bermúdez-Millan A, Segura-Pérez S. Impact of peer nutrition education on dietary behaviors and health outcomes among Latinos: a systematic literature review. J Nutr Educ Behav. 2008;40:208-225.

2. Cohen N, Carbone ET, Beffa-Negrini PA. The design, implementation, and evaluation of online credit nutrition courses: a systematic review. J Nutr Educ Behav. 2011;43:76-86.

3. Bandayrel K, Wong S. Systematic literature review of randomized control trials assessing the effectiveness of nutrition interventions in community-dwelling older adults. J Nutr Educ Behav. 2011;43:251-262.

4. Kelly NR, Mazzeo SE, Bean MK. Systematic review of dietary interventions with college students: directions for future research and practice. J Nutr Educ Behav. 2013;45:304-313.

5. Atoloye AT, Savoie-Roskos MR, Guenther PM, Durward CM. Effectiveness of Expanded Food and Nutrition Education Program in changing nutritionrelated outcomes among adults with low income: a systematic review. J Nutr Educ Behav. 2021;53:691-705.

6. Fultz AK, Sundermeir SM, Katz S, Robson SM. More frequent food shopping may promote fruit and vegetable intake: a systematic review. J Nutr Educ Behav. 2021;53:957-965. 